\title{
0 Conceito de Empreendimento Econômico Solidário: Por uma Abordagem Gradualista
}

\author{
Luiz Inácio Gaiger ${ }^{1}$ \\ Adriane Ferrarini ${ }^{1}$ \\ Marília Veronese ${ }^{1}$ \\ ${ }^{1}$ Universidade do Vale do Rio dos Sinos (Unisinos), São Leopoldo, RS. E-mail: \\ gaiger@unisinos.br
}

\section{INTRODUÇÃO}

$\mathrm{O}$ rganizações econômicas alternativas ao mercado e ao Estado, ou às lógicas respectivamente das empresas de fins lucrativos e da administração pública, são um fato contemporâneo corrente que tem ensejado investigações empíricas, análises e teorizações sucessivas (Razeto, 1990; Santos, 2002a; Nyssens, 2006). Os atores sociais engajados em sua promoção referem-se a essas organizações aludindo por vezes a conceitos consagrados historicamente e classificando-as, então, como formas novas de associativismo ou cooperativismo. No contexto latino-americano, contudo, tem sido mais comum designá-las por meio de expressões surgidas na década de 1990, como economia popular solidária ou simplesmente economia solidária. Esse último termo ganhou vigência e oficialidade no Brasil à medida que despontaram iniciativas econômicas notabilizadas por suas práticas de autogestão e de mutualismo na esfera econômica, vindo a abarcar variadas modalidades de organização, como unidades informais de geração de renda, associações de produtores e consumidores, comunidades autóctones e cooperativas populares, dedicadas à produção de bens, à prestação de serviços, à comercialização e ao crédito.

Até o momento, apenas as associações e as cooperativas dispõem de um marco jurídico próprio no Brasil. Esse quadro legal, porém, mostra-se inapropriado às organizações que se multiplicaram nas últimas décadas como partícipes de uma nova onda de solidarismo, pois elas se

DADOS - Revista de Ciências Sociais, Rio de Janeiro, vol. 61, no1, 2018, pp. 137 a 169.

http://dx.doi.org/10.1590/001152582018149 
contrapõem aos modelos já institucionalizados, especialmente a seu principal representante, o cooperativismo. Encontram-se em busca de uma identidade institucional e de um arcabouço jurídico condizente, de cuja necessidade não restam dúvidas (Da Silva e Silva, 2015; Gaiger, 2015). De par com a economia solidária, surgiu então um conceito de ampla aceitação: empreendimento econômico solidário. Pelas mesmas razões, seja para fins de promoção ou de estudos, os empreendimentos econômicos solidários (doravante, EES) não poderiam ser bem apreendidos somente a partir do formato jurídico oficial que adotam: quando existente, dito formato representa em geral uma solução paliativa para que possam funcionar no atual ambiente econômico. De mais a mais, boa parte dos EES é constituída de grupos informais, que não se regem por nenhum dispositivo legal, mas por normas internas próprias.

Nessas circunstâncias, inexistem critérios claros e de uso comum para fins de diferenciação e classificação dos EES, sendo inapropriado suprir essa lacuna recorrendo a argumentos formais. De parte dos promotores da economia solidária, e graças a uma convergência notória e singular no caso brasileiro, o recurso tem sido apoiar-se em uma definição política comum de EES para fins de demarcá-los das formas subordinadas ou capitalistas de economia e de enfatizar o sentido alternativo e transformador da economia solidária. Sua virtude principal reside na unidade que propicia entre os atores e na força de convicção que empresta às variadas iniciativas que buscam impulsionar as práticas solidárias. Mas, haja vista sua carga normativa, o conceito traz uma desvantagem por sua tendência natural à hipostasia, a ser deificado e contraposto de forma dicotômica e linear a toda economia não solidária. Além disso, deixa em plano secundário uma série de distinções úteis a serem feitas entre tipos de EES, não exatamente no intuito de incluí-los ou excluí-los da economia solidária, mas de visualizar os traços relevantes que os qualificam e singularizam, a fim de dispô-los naquelas posições variáveis que ocupam dentro do campo mais amplo das formas híbridas (Laville, 2006) de economia.

Especialmente para fins de estudo e conceituação dos EES, mas com ganhos estimáveis para a ação política, conviria adotar uma abordagem gradualista, como buscaremos demonstrar. Ela não implica descartar categorias emanadas da práxis social, como as da esfera pública, mas inseri-las num quadro de análise que incorpore aquelas propriedades dos EES, mesmo sutis, que à luz de estudos se tenham revelado estruturantes de sua natureza sui generis e, também, explicativas de 
suas linhas de diferenciação e dos padrões correlatos. Em outras palavras, trata-se de passar de um enfoque normativo a uma conceituação ideal-típica, como preconizava Max Weber. Tal convicção provém de um conjunto de pesquisas empíricas e de elaborações teóricas - incluindo o conceito de EES (Gaiger, 2009a) e questões relacionadas à lógica econômica solidária (Ferrarini e Veronese, 2010) - realizadas há mais de 15 anos no âmbito do Grupo de Pesquisa em Economia Solidária e Cooperativa (Grupo EcoSol), vinculado ao Programa de Pós-Graduação em Ciências Sociais da Universidade do Vale do Rio dos Sinos (Unisinos). Essa perspectiva de análise, adicionalmente, se tem beneficiado nos últimos anos da inserção dos autores desse artigo em um projeto internacional ${ }^{1}$ que a adota de modo similar para fins de comparação, em diversos países e continentes, entre as modalidades de produção e de prestação de serviços que se distinguem da economia pública e da economia privada com ânimo de lucro, com referência em particular às empresas sociais (Defourny e Nyssens, 2012, 2013) e, no Sul, às organizações de economia social e solidária (Gaiger, 2009b).

A contribuição pretendida por esse artigo tem assim um propósito metodológico, relacionado ao desenvolvimento de uma abordagem dos EES com fins conceituais e comparativos, cujo desdobramento teórico resultará em um modelo típico-ideal e, de conformidade com a abordagem gradualista, em considerações sobre organizações afins e campos de práticas correlatos. Em sua primeira seção, retomamos em grandes linhas o processo de convergência havido entre os atores sociais no Brasil, o que favoreceu sua unidade em torno de uma visão comum da economia solidária. A segunda seção será destinada ao método de conceptualização proposto e a seu resultado - o conceito ideal-típico de empreendimento econômico solidário - com a sua decomposição em componentes cuja operacionalização através de indicadores almeja favorecer o exame de realidades empíricas. Na terceira, sob o prisma da abordagem gradualista em tela, serão discutidos aspectos conceituais relacionados a organizações congêneres que apresentam afinidades com alguns dos traços definidores dos EES, mas se situam em uma órbita limítrofe em decorrência de suas propriedades singulares e contrastantes. A última seção estenderá a mesma perspectiva gradualista à consideração de campos de práticas próximos ou interseccionados com a economia solidária, com destaque ao terceiro setor e suas principais manifestações no Brasil.

DADOS - Revista de Ciências Sociais, Rio de Janeiro, vol. 61, no 1, 2018 


\section{UMA CONVERGÊNCIA SOCIAL E POLÍTICA SINGULAR}

O termo empreendimento econômico solidário, com sua sigla EES, foi adotado gradativamente no Brasil no correr dos anos 1990, mesmo período em que a expressão economia solidária conquistou a preferência em relação a designações correntes, como socioeconomia solidária, economia popular solidária ou economia de autogestão ${ }^{2}$. Desse debate participaram inúmeras organizações não governamentais, sindicatos, entidades de representação, instituições acadêmicas e gestores públicos, ao lado de lideranças populares forjadas na experiência prática dos empreendimentos. Na esteira de encontros regionais e nacionais, essa convergência progressiva conduziu em 2003 à criação do Fórum Brasileiro de Economia Solidária (FBES), como elo aglutinador, formador de consensos, e como instância de representação. No bojo das negociações relacionadas ao programa e à estrutura de governo do primeiro mandato do presidente Lula, criou-se simultaneamente a Secretaria Nacional de Economia Solidária, órgão de interlocução com a sociedade e ente articulador e promotor da ação pública. Em tais circunstâncias e à medida do seu uso, o termo EES serviu desde então a diferentes finalidades, quer para delimitar o universo de atuação de entidades civis ou a abrangência dos programas de governo, quer para dar unidade às organizações participantes de redes, fóruns e outras formas de mobilização, quer ainda para fins acadêmicos, em pesquisas e trabalhos de teorização.

Esses empregos simultâneos do termo deixaram-no compreensivelmente em um estado de relativa imprecisão, sustentando uma unidade lexical cujo sentido encerrava perspectivas distintas, latentes, ora com propósitos analíticos, orientados a constatações e explicações sobre a realidade, ora de conotação ideológica e programática, relacionada a premissas e objetivos de transformação da realidade. Nessa segunda frente, o conceito foi objeto de exaustivos debates, acordos e revisões, sobretudo por obra dos principais agentes do campo, como os citados, refletindo-se por fim em deliberações do Conselho Nacional de Economia Solidária ${ }^{3}$. Desse processo de construção a muitas mãos resultou um marco de referência aceito amplamente, um denominador comum no tocante às características essenciais (efetivas ou desejáveis) dos EES.

Dita convergência deu passos importantes nas Conferências Nacionais de Economia Solidária, realizadas em 2006 e 2010. O Documento Final da $1^{a}$ Conferência ${ }^{4}$ assim dispõe: 
3. A Economia Solidária é, pois, um modo de organizar a produção, distribuição e consumo, que tem por base a igualdade de direitos e responsabilidades de todos os participantes dos empreendimentos econômicos solidários. Os meios de produção de cada empreendimento e os bens e/ou serviços neles produzidos são de controle, gestão e propriedade coletiva dos participantes do empreendimento. Igualmente, há associações, cooperativas e grupos informais de consumidores, pequenos produtores ou prestadores de serviços, individuais ou familiares, que trabalham em separado (cada qual em seu estabelecimento), mas realizam em comum a compra de seus insumos, a comercialização de seus produtos ou o processamento dos mesmos (...). 5. As iniciativas de Economia Solidária têm em comum a igualdade de direitos, de responsabilidades e oportunidades de todos os participantes dos empreendimentos econômicos solidários, o que implica autogestão, ou seja, participação democrática com exercício de poder igual para todos, nas decisões, apontando para a superação da contradição entre capital e trabalho (p. 2).

Anos depois, as características definidoras dos EES foram ordenadas no documento preparatório à 3 a Conferência Nacional ${ }^{5}$ (realizada em 11/2014), nele incorporando-se decisões das conferências anteriores. Segundo a Secretaria Nacional de Economia Solidária e o Conselho Nacional de Economia Solidária, autores do documento, os EES devem:

I. Ser uma organização coletiva, singular ou complexa, cujos participantes ou sócios são trabalhadores do meio urbano ou rural;

II. Realizar atividades de natureza econômica, socioambiental e cultural que devem ser as razões primordiais da existência da organização;

III. Ser uma organização de autogestão cujos participantes ou sócios exerçam coletivamente a gestão das atividades econômicas e a decisão sobre a partilha dos seus resultados, através da administração transparente e democrática, soberania da assembleia e singularidade de voto dos sócios, cumprindo o seu estatuto ou regimento interno;

IV. Ser uma organização permanente, considerando tanto os empreendimentos que estão em funcionamento quanto aqueles que estão em processo de implantação, desde que o grupo esteja constituído e as atividades econômicas definidas (p. 21).

Essa concepção, reiterada quanto à natureza e aos traços típicos dos EES, orientou iniciativas conjuntas em favor de uma nova legislação

DADOS - Revista de Ciências Sociais, Rio de Janeiro, vol. 61, no 1, 2018 
nacional apropriada à economia solidária. Uma campanha nacional de Lei de Iniciativa Popular, liderada pelo FBES, caracteriza os EES de forma bastante semelhante a propostas oriundas do Congresso Nacional, consubstanciadas no Projeto de Lei 4.685/2012, que institui uma política nacional e um fundo específico para a economia solidária. Seu art. $4^{\circ}$ considera como empreendimentos econômicos solidários as organizações que possuam concomitantemente as seguintes características:

I - Ser uma organização coletiva e democrática, singular ou complexa, cujos participantes ou sócios são trabalhadores do meio urbano ou rural;

II - Exercer atividades de natureza econômica como razão primordial de sua existência;

III - Ser uma organização autogestionária, cujos participantes ou associados exerçam coletivamente a gestão das atividades econômicas e a decisão sobre a partilha dos seus resultados, através da administração transparente e democrática, soberania assemblear e singularidade de voto dos sócios, conforme dispuser o seu estatuto ou regimento interno;

IV - Ter seus associados direta ou preponderantemente envolvidos na consecução de seu objetivo social;

V - Distribuir os resultados financeiros da atividade econômica de acordo com a deliberação de seus associados, considerando as operações econômicas realizadas pelo coletivo;

VI - Realizar pelo menos uma reunião ou assembleia trimestral para deliberação de questões relativas à organização das atividades realizadas pelo empreendimento;

VII - Destinar parte do seu resultado operacional líquido para auxiliar outros empreendimentos equivalentes que estejam em situação precária de constituição ou consolidação, no desenvolvimento comunitário e para a formação política, econômica e social dos seus integrantes.

$\S 1$ 을 Para efeitos desta lei, os empreendimentos econômicos solidários podem assumir diferentes formas societárias, desde que contemplem as características do caput 4 .

$\S 2$ 으ão serão considerados empreendimentos econômicos solidários aqueles cujo objeto social seja a intermediação de mão de obra subordinada.

Esses exemplos bastam para demonstrar o consenso existente em torno do conceito de EES. Ao mesmo tempo, servem para realçar algumas das suas peculiaridades: a ênfase colocada na sua função econômica; 0 
fato de tais organizações deverem ser geridas pelos trabalhadores consumidores e usuários que tomam parte das suas atividades, sendo inerente aos membros a qualidade de sócios e detentores do capital social; a finalidade de obtenção de resultados econômicos e a legitimidade de sua redistribuição entre os membros, especialmente em contrapartida do trabalho por eles prestado, critério que leva a diferenciar tais excedentes da geração e apropriação privada de lucro; por fim, o caráter autogestionário dos EES, um atributo que vai além da governança democrática, usual em definições no âmbito da economia social (Bouchard, Cruz Filho e Saint-Denis, 2011).

Esse entendimento e essas definições contaram com a participação pari passu de estudiosos e instituições acadêmicas, com isso obtendo a chancela científica quanto à sua adequação geral à realidade, mas em contrapartida ficando constantemente sob o escrutínio de estudos motivados por diferentes prismas de problematização e análise ${ }^{6}$. A expansão da economia solidária explica o maior interesse de segmentos acadêmicos já antes ocupados com temas afins, como o associativismo, o cooperativismo e a autogestão operária. Mas foi a novidade das experiências solidárias, em uma época de descrédito dos modelos alternativos à economia de mercado, o que atraiu uma nova geração de acadêmicos, cujo entusiasmo e denodo terminaram quebrando resistências e contagiando pesquisadores experientes, diante de um novo fato social que já não podia passar despercebido. Estudos de maior envergadura deram a seguir qualidade teórica e analítica à produção científica, à medida que a economia solidária se integrou à agenda de pesquisa de centros de referência (Leite, 2009; Lima, 2012).

Como pano de fundo desse trabalho colaborativo entre atores sociais, acadêmicos e gestores públicos, deve-se ter em vista o processo de transição democrática transcorrido no Brasil nos anos 1980 e 1990, cujos desdobramentos ainda se fazem sentir, especialmente porque engendraram um padrão complexo de relações entre a sociedade civil e o Estado (Silva e Oliveira, 2011). Nesse contexto, atores diversos, como líderes dos movimentos sociais, agentes de organizações não governamentais, intelectuais, acadêmicos e representantes governamentais, jogam papéis múltiplos, de acordo com seu campo social de origem, suas possibilidades de trânsito de um campo a outro e seus ativos materiais, simbólicos e propriamente políticos. Assim, a produção científica sobre a economia solidária não se tem realizado apenas no interior de recintos universitários. Quem pesquisa o tema, além de atribuições 
típicas como a docência e a orientação de trabalhos acadêmicos, usualmente atua em projetos de apoio às experiências solidárias e participa dos circuitos de debate, quando não de instâncias representativas e deliberativas, como os fóruns e redes; tais estudos são desenvolvidos em conexão com demandas provenientes dos atores, estando amiúde relacionados a programas públicos que estimulam ou financiam análises e avaliações.

A atividade acadêmica contribui particularmente para que a apreensão social da economia solidária não se limite a seus traços aparentes ou se deixe iludir por fatos altissonantes, terreno em que prosperam, com a sua lógica assertiva peculiar, tanto as visões ideológicas quanto as formulações políticas. Assim, opondo-se ao senso comum, a primeira pesquisa nacional realizada no Brasil concluiu que a economia solidária não era um fenômeno reflexo, de mera reação ao desemprego e à precarização social, situação em que estaria cumprindo um papel de variável dependente da dinâmica do mercado de trabalho. Ao contrário, sua emergência se explicaria por um conjunto de fatores, como as relações de reciprocidade existentes entre os trabalhadores que tomam parte de tais iniciativas e o valor que atribuem às alternativas de trabalho que não os submetam ao jugo direto das relações assalariadas. Uma vez em ação, os empreendimentos passam a funcionar como laboratórios, micro totalidades em que surgem novos desafios, tais como equacionar os interesses individuais e coletivos e firmar estratégias coerentes a partir de decisões consensuais. Os impasses com que se depara a prática concreta dos EES não comportam soluções simples e põem em xeque as teses mais radicais em defesa da autogestão permanente, ou da supressão de toda forma de divisão do trabalho, cuja viabilidade pressupõe indivíduos não apenas inteiramente altruístas, mas multifuncionais e dotados de plena racionalidade comunicativa (Gaiger, 2004).

Outro contributo de interesse propiciado pelos estudos acadêmicos consistiu em estampar a variedade de circunstâncias em que os EES iniciam e desenvolvem suas atividades, fato que leva a descartar enfoques com alta carga teleológica quanto a seu sentido e seu devir. Essa diversidade de certa forma permanecia encoberta, haja vista a preocupação reinante, no terreno das ações, de dar visibilidade pública à economia solidária e, para isso, unificá-la. Ademais, a reflexão teórica que tais fatos emergentes vinham suscitando centrava-se em seu potencial transformador, na possibilidade de tais empreendimentos 
incrementarem o leque das formas não capitalistas de produção (Santos, 2002a): eles corresponderiam a uma germinação de formas de economia alternativa, distintas da lógica mercantil capitalista, e de alternativas econômicas que, se tornando viáveis, seriam capazes de assegurar sua reprodução social. Considerados como uma nova totalidade, os empreendimentos solidários seriam artífices de outra economia, sendo essa a questão que dominou os debates acadêmicos por um longo tempo (Gaiger, 2012a) ${ }^{7}$.

Contudo, essas possibilidades não estão previamente asseguradas; devem ser entendidas como tendências que se materializam com maior ou menor intensidade segundo as condições objetivas e subjetivas que afetam cada iniciativa, cujo desenvolvimento é variável e depende não apenas do cenário em que se encontra, mas igualmente do crédito e da impulsão que venha futuramente a receber. Em que pese o mérito de apontar aspectos singulares e promissores das experiências de economia solidária, o conceito acadêmico de EES, nessas condições incertas e cambiantes, deveria manter-se como uma instância de questionamento da realidade, como instrumento heurístico para o entendimento dos fatos, sem fins preditivos.

Assim, à contracorrente das abordagens englobantes e até certo ponto indiscriminantes, o reconhecimento da diversidade de situações conduziu parte dos trabalhos acadêmicos a um depuramento conceitual progressivo, em nosso caso seguindo as formulações seminais de Luis Razeto $(1983 ; 1990 ; 1993)$ acerca das empresas de economia popular. Já no início dos anos 1980, esse autor distinguia, no mundo dos pobladores das periferias urbanas do Chile, grupos que criavam organizações econômicas coletivamente. Para tanto, se valiam de recursos pessoais, postos em comum, e da ajuda mútua. Algumas dessas organizações logravam superar o simples patamar de subsistência e aportavam melhorias à qualidade de vida, propiciando em certos casos margens de acumulação e crescimento econômico, graças a práticas e valores como a solidariedade, a cooperação e a autonomia. Convertiam-se em empresas de economia popular, nas quais predominavam relações de reciprocidade e cooperação, bem como certo hibridismo entre arranjos formais e informais e entre práticas não mercantis e aquelas integradas ao mercado (Nyssens, 1996). Mesmo pressionadas por dilemas de sobrevivência, assumiram um papel de resistência em face da exclusão política, social e cultural imposta aos pobladores.

DADOS - Revista de Ciências Sociais, Rio de Janeiro, vol. 61, no 1, 2018 
Evoluções posteriores conduziram ditas experiências a gerar trabalho e renda duradouramente, constituindo-as como uma via alternativa de novos sujeitos econômicos. Nisto consistiria a natureza sui generis dos EES, tal como o conceito foi concebido e a seguir introduzido no Brasil: ele não abrange todos os empreendimentos econômicos movidos pela solidariedade, mas apenas aqueles que a transformam na viga mestre de sua dinâmica interna e de suas estratégias. Ingressam com isso em ciclos virtuosos que asseguram sua viabilidade e justificam a persistência de seus membros, mesmo diante de pesados obstáculos e de um contexto mais geral em regra severamente adverso (Gaiger, 1996; 2006).

\section{UM CONCEITO IDEAL-TÍPICO}

Nessa ótica, o conceito teórico não daria conta da totalidade dos EES por abarcar suas diversas expressões concretas, mas sim graças ao fato de postular um modelo de referência quanto aos requisitos a que são confrontadas ditas organizações para assegurarem sua sobrevivência e seu desenvolvimento. Tais requisitos, não sendo contraditórios com a estrutura interna dos EES, podem encontrar-se em estado de potência, como possibilidades reais. O modelo funciona não como síntese do real, mas como um instrumento cuja validez reside em interpelar a realidade empírica de um ponto de vista julgado adequado e relevante. Em uma palavra, trata-se de um conceito assente no método weberiano dos tipos-ideais.

Conforme Max Weber, um tipo-ideal corresponde a um quadro de pensamento, não à realidade em si e tampouco a alguma realidade presumida como autêntica ou exemplar. "Tem antes o significado de um conceito limite puramente ideal, em relação ao qual se mede a realidade a fim de esclarecer o conteúdo empírico de alguns de seus elementos importantes, e com a qual é comparada" (Weber, 1989:106). O tipo-ideal reúne um conjunto de aspectos atinentes a uma classe de fenômenos, cuja presença se considera necessária para que ditos fenômenos existam, de acordo com a perspectiva e as premissas teóricas do investigador, ao mesmo tempo inevitáveis e parciais. Trata-se de um instrumento heurístico para a busca de conexões causais essenciais, e não meramente acidentais, próprias àquela classe de fenômenos. Serve a comparações entre tais enunciados e os casos empíricos singulares ${ }^{8}$.

Para Weber, a utilização de tipos-ideais é indispensável, devendo-se recorrer a eles de forma consciente para que os interesses e os pressu- 
postos da análise empreendida não fiquem implícitos e, desse modo, fora de controle. Seria impossível investigar temas relacionados a noções como capitalismo, democracia ou justiça, sem um modelo teórico de referência. O tipo-ideal, por conseguinte, clarifica, delimita e legitima a perspectiva de análise empregada no exame de casos empíricos.

Não seria diferente na economia solidária, como exemplifica Razeto ao postular que a peculiaridade de tais empreendimentos reside no acionamento do Fator C:

a formação de um grupo, associação ou comunidade, que opera cooperativa e cordialmente, proporciona um conjunto de benefícios a cada integrante e um melhor rendimento e eficiência à unidade econômica como um todo, devido a uma série de economias de escala, economias de associação e externalidades, implicadas na ação comunal e comunitária (Razeto, 1993:40-41).

Esses efeitos tangíveis e positivos resultam em

uma particular produtividade dada pela presença e crescimento do referido elemento comunitário, análoga à produtividade que distingue e pela qual se reconhecem os demais fatores econômicos (idem).

Como esclarece o mesmo autor, tais enunciados devem ser compreendidos como uma proposição de tipo-ideal:

Esses diferentes aspectos da produção, distribuição e consumo na economia solidária devem ser entendidos como a expressão teórica de comportamentos tendenciais, e não como madura e completa manifestação do que efetivamente existe na realidade. (...) As teorias sociais e econômicas identificam "modelos puros", que, na realidade empírica, não encontram materialização cabal, mas que existem e operam efetivamente enquanto potencialidades parcialmente realizadas, como racionalidades que presidem e orientam os comportamentos, como tendências que apontam para identidades em formação (ibidem:44-45).

Considerar o Fator $\mathrm{C}$ como um elemento fulcral da racionalidade ${ }^{9}$ dos EES significa admitir que o êxito dessas organizações depende do acionamento dos fatores produtivos capazes de incrementá-lo como força ao mesmo tempo social e econômica. EES seriam aqueles empreendimentos que conjugam organicamente práticas de participação e cooperação com práticas orientadas à eficiência e à viabilidade econômica. Nessa acepção ideal-típica, em outras palavras, o êxito econômico dos

DADOS - Revista de Ciências Sociais, Rio de Janeiro, vol. 61, no 1, 2018 
EES dependeria de fatores cujo efeito positivo seja proporcional ao caráter solidário por eles incorporado. Para isso, o trabalho seria levado a seu pleno rendimento como trabalho associado, supondo vínculos de reciprocidade (Gaiger, 2017) condizentes com a natureza coletiva e colaborativa dos EES. Converter a dimensão social em alavanca econômica, ou em uma força produtiva específica, seria o que confere aos EES vantagens comparativas diferenciais em relação a organizações similares, mas não solidárias.

Pesquisas empíricas com esse enfoque corroboraram a tese de que os empreendimentos, quando bem-sucedidos, se enquadram em uma lógica calcada no envolvimento dos membros com a gestão e o trabalho, sendo esse fato o que lhes proporciona algum nível de acumulação e crescimento, estabilidade e viabilidade. Desenvolvem uma racionalidade peculiar, simultaneamente econômica e social (Gaiger, 2006; 2007a). Segundo os resultados obtidos sucessivamente por essa ótica investigativa, os EES podem ser então definidos esquematicamente como organizações cuja virtude peculiar reside na integração do espírito empreendedor - no sentido da busca planejada de resultados e do aprimoramento dos fatores produtivos - com o espírito solidário, de tal sorte que a cooperação funcione como fator de racionalização econômica, produzindo efeitos tangíveis e vantagens reais comparativamente às demais alternativas de ocupação e renda ao alcance dos trabalhadores em questão. Um segundo equacionamento se realiza no sentido de conciliar uma lógica ou razão instrumental - orientada pelo realismo e pragmatismo necessários à viabilização a curto prazo dessas alternativas econômicas - com uma lógica ou razão expressiva e projetiva, imersa em valores e em aspirações de mudança pessoal e social que demandam altruísmo, engajamento e convicções quanto à valia e às possibilidades de tais transformações (Gaiger e Corrêa, 2010).

Do ponto de vista de sua racionalidade intrínseca, em termos típicoideais os EES caracterizam-se sumariamente pelas relações dialéticas, de um lado entre solidarismo e empreendedorismo, de outro lado entre razão pragmática e razão projetiva. Ditas relações compõem o pano de fundo à frente do qual se desenvolve a atividade econômica, se realiza a gestão coletiva e se cumpre a missão social de tais organizações. De acordo com esse método de conceptualização, o notório polimorfismo das diversas iniciativas populares incluídas no rol da economia solidária não impede que se opere uma redução das mesmas a esses traços essenciais, com o objetivo de identificar as propriedades e rela- 
ções constituintes de sua estrutura e de sua dinâmica singular, do ponto de vista ideal-típico escolhido. De mais a mais, como advertia Weber, "a construção de tipos ideais abstratos não interessa como um fim, mas única e exclusivamente como meio de conhecimento", valendo apenas o critério de eficácia quanto ao esclarecimento que aportam em relação aos fenômenos concretos, "tanto nas suas conexões como no seu condicionamento causal e na sua significação" (Weber, 1989:108).

Assim, seria justo dizer que no Brasil existem duas utilizações simultâneas do conceito de EES. A primeira, para fins de caracterização, inclusão e promoção, refere-se aos traços elementares que os empreendimentos devem apresentar para serem enquadrados na economia solidária. Como vimos, tais parâmetros gerais foram estabelecidos de forma consensual, embora permaneçam sujeitos a questionamentos e revisões, em compasso com a evolução desse campo de práticas e com as formas de entendimento predominantes. A segunda utilização, mais restrita e discriminante, aponta as propriedades julgadas típicas e explicativas com vistas à qualificação dos empreendimentos, sua diferenciação e comparação, para uma ótica dada de análise. Nesse caso, como observamos, a construção e a aplicação do conceito de EES dependem de critérios ex ante, próprios a cada investigação.

De acordo com os interesses ou as situações de pesquisa, as conceptualizações podem desdobrar-se em mais de um modelo analítico de referência, flexionando alguns dos seus elementos ou agregando novos aspectos, compatíveis com o modelo original. É preciso ademais operacionalizar os conceitos, desmembrando-os em características passíveis de confrontação empírica. Com essa finalidade, nosso tipo-ideal de EES apresenta-se decomposto em três atributos gerais, aos quais correspondem quinze critérios de qualificação, por sua vez traduzíveis em indicadores observacionais ${ }^{10}$. Cada um dos atributos desdobra-se em cinco critérios, servindo os mesmos como gradientes que indicam variações entre os EES observados quanto à forma e ao grau de atendimento do atributo geral correspondente.

O primeiro critério destina-se a demonstrar preliminarmente a conformidade dos casos empíricos ao atributo em questão e, por conseguinte, se são classificáveis como EES daquele ponto de vista. Tais critérios um para cada atributo - são coerentes com as características básicas dos EES definidas no Brasil por meio do consenso social já mencionado, o que lhes confere legitimidade e estabilidade. Os demais crité- 
rios foram agregados com base em estudos sucessivos do Grupo Eco$\mathrm{Sol}^{11}$. O último critério, em cada atributo geral, indica o grau mais elevado de adequação que os EES presumivelmente podem atingir sob o prisma subjacente ao conceito teórico. Embora se trate de um dispositivo de análise, entre outros imagináveis, estima-se que quanto mais estejam dotados das propriedades de cada atributo geral, mais os EES reúnem as condições e os motivos necessários ao exercício da racionalidade solidária dada pelo conceito ideal-típico.

Integrando-se assim os elementos do modelo teórico com aqueles da definição usual, que delimita previamente o universo de análise, tem-se a conceituação a seguir:

\section{EES}

Organizações suprafamiliares, criadas e mantidas pela associação voluntária de trabalhadores, consumidores e usuários para atenderem necessidade e aspirações econômicas, sociais e culturais comuns, apresentando as seguintes características:

\begin{tabular}{|l|}
\hline 1. Atividade econômica \\
\hline 1.1. Atividade econômica contínua. \\
\hline 1.2. Viabilidade econômica. \\
\hline 1.3. Capital de propriedade comum dos sócios. \\
\hline 1.4. Envolvimento dos sócios na gestão. \\
\hline 1.5. Trabalho coletivo preponderantemente exercido pelos sócios. \\
\hline 2. Compromisso social \\
\hline 2.1. Distribuição equitativa dos ganhos e benefícios entre os membros. \\
\hline 2.2. Relações equânimes e colaborativas com terceiros. \\
\hline 2.3. Militância em causas sociais. \\
\hline 2.4. Ações de fortalecimento e transformação institucional. \\
\hline 2.5. Engajamento em movimentos de transformação social. \\
\hline 3. Gestão democrática \\
\hline 3.1. Processos participativos de direção e administração. \\
\hline 3.2. Idêntico poder de decisão entre os sócios. \\
\hline 3.3. Indiscriminação e igualdade social entre os membros ${ }^{12}$. \\
\hline 3.4. Autonomia institucional. \\
\hline 3.5. Envolvimento cotidiano dos membros nas decisões. \\
\hline
\end{tabular}

Os atributos gerais e os critérios de qualificação assim se apresentam e justificam: 


\section{Atividade econômica}

A atividade econômica compreende principalmente a produção de bens, a comercialização e a prestação de serviços pelos sócios, além de formas de apoio à sua produção individual ou familiar, como o fornecimento de insumos e equipamentos ou a oferta de crédito. Inclui também a aquisição de bens de consumo e a disponibilização de serviços relacionados à moradia, saúde, educação etc. Alguns EES destinam-se ao provimento de serviços públicos, como o abastecimento de água e vias de transporte, ou ainda ao fortalecimento institucional de entidades comunitárias e associativas. A economia é então compreendida em sentido amplo, sem limitar-se a bens e serviços produzidos para o mercado e sem descartar atividades não monetárias, desde que envolvam trabalho e recursos para a sua realização.

Entende-se que a atividade econômica deve ser uma finalidade primordial para o EES, não sendo, portanto, esporádica ou casual (critério 1.1). O quesito de viabilidade significa que o EES deve garantir, principalmente com meios próprios, a continuidade de sua atividade econômica, assumindo então os custos e os riscos inerentes, sem depender de aportes externos cuja disponibilidade escape ao seu domínio (1.2). O capital que constitui o EES ou que é utilizado para essa atividade deve pertencer aos sócios, em parte como propriedade comum (1.3). A atividade econômica deve contar com o envolvimento dos sócios nas deliberações, no planejamento e na execução, evitando assim que a divisão técnica das tarefas culmine em uma divisão social do trabalho, apartando gestores e executores, trabalhadores intelectuais e manuais (1.4). Por fim, espera-se que o trabalho seja uma atividade coletiva, realizada majoritariamente pelos sócios, sem forte dependência da colaboração de voluntários e sem lançar mão indiscriminadamente da força de trabalho assalariada, devido à natureza intrinsecamente assimétrica e tendencialmente utilitária de tais relações (1.5).

\section{Compromisso social}

Esse atributo implica que o EES desenvolva atividades com sentido e utilidade pública, não se restringindo a gerar benefícios para seus integrantes e não agindo contra os interesses da coletividade. Corresponde à missão social, termo corrente no âmbito da economia social ao Norte global, no sentido de consignar a primazia da vocação social das organizações em relação à sua finalidade econômica (Nyssens, 2006).

DADOS - Revista de Ciências Sociais, Rio de Janeiro, vol. 61, no 1, 2018 
No caso dos EES, diríamos, prevalece uma articulação entre a dimensão social e econômica, não a predominância de uma sobre a outra. Postular de outro modo acarreta o problema de conceber implicitamente o econômico como algo antissocial em si mesmo (ou seja, desvinculado dos aspectos sociais e coletivos), por conseguinte associando-o metonimicamente à economia de mercado capitalista e a seu primado utilitarista. Dentro de um marco substantivo e plural da economia, o social e o econômico se integram em diferentes dosagens e modos, sendo essa aliás uma singularidade relevante da economia solidária (Gaiger e Laville, 2009; Gardin e Laville, 2017).

O compromisso social dos EES pode ficar implícito, sem um alvo preciso. Funciona, nesses casos, ora como uma motivação genérica que engendra iniciativas um tanto ao sabor das circunstâncias, ora como um balizador ético de suas práticas ou, ainda, como um princípio justificador de sua atividade econômica, a exemplo da disseminação da agroecologia, da valorização do artesanato ou da promoção do comércio justo. Para explicar essas conexões, convém relembrar uma peculiaridade da economia solidária em relação à economia social: nessa última, associações e organizações sem fins lucrativos obram por uma causa social, em geral beneficiando pessoas em situações de privação. Na economia solidária, de modo geral são essas mesmas pessoas, pobres ou discriminadas, que se organizam para defender coletivamente seus direitos e interesses. Seu êxito nesta empreitada já significa cumprir uma função social em prol de pessoas carentes de renda e recursos. Assim, faz sentido que os excedentes que resultam das operações econômicas do EES sejam destinados equitativamente à remuneração do trabalho executado pelos sócios (critério 2.1), bem como à melhoria de seu bem-estar e igualmente das pessoas e comunidades situadas no raio de ação dos EES.

O compromisso social dos EES se estende a seus vínculos com outras organizações, pois coerentemente tais relações devem observar princípios de equidade, colaboração e justiça (2.2). Exemplificam-no a intercooperação técnica, que estimula a solidariedade generalizada. O terceiro quesito do compromisso social dos EES é seu engajamento por causas específicas, como o combate à pobreza e às desigualdades de gênero, a defesa de povos e comunidades tradicionais e o desenvolvimento local (2.3). As ações de caráter institucional, por sua vez, dizem respeito aos embates pelo reconhecimento público das demandas dos EES e pela promulgação de leis e outros dispositivos institucionais que 
as contemplem (2.4). Supõem engajamento em organizações de articulação política e econômica entre os EES, como redes e fóruns, e implicam competências específicas, designadas por alguns autores de institutional entrepreneurship (Lawrence e Suddaby, 2006). O último critério, relativo ao envolvimento dos EES com movimentos de transformação, no intuito de construir alternativas sociais emancipatórias, é revelador do seu grau de posicionamento crítico e da transcendência que reconhecem ou procuram imprimir em suas ações (2.5).

\section{Gestão democrática}

O caráter alternativo dos EES supõe inovações diante da estrutura hierárquica e das relações de poder que preponderam em organizações econômicas convencionais. A gestão democrática estimula a participação e garante que as deliberações fundamentais sejam tomadas pelo conjunto de sócios; é a forma que mais se adequa à natureza coletiva e igualitária da economia solidária. Compreende desde o princípio clássico "um sócio, um voto" até a participação igualitária de sócios homens e mulheres.

Diversos mecanismos podem assegurar que a direção e a administração se realizem com a participação dos sócios (critério 3.1), a começar pela eleição livre e direta dos dirigentes, a renovação periódica dos quadros diretivos e a regularidade de consultas e reuniões decisórias. A igualdade de poder de decisão entre os sócios implica que seu exercício independa de suas quotas de capital ou de suas operações econômicas no EES (3.2). É também necessário garantir que a participação dos membros não seja afetada pela desigualdade social reinante, especialmente no tocante ao gênero, a aspectos geracionais ou ligados à raça $\mathrm{e}$ etnia (3.3). Isto tem sido feito por meio de medidas coercitivas ou por políticas de discriminação positiva. Mas para que suas decisões sejam efetivas, o EES deve desfrutar de autonomia institucional, mantendo sob o seu domínio as diversas e inevitáveis interdependências que mantém em relação a organizações e agentes externos (3.4). O envolvimento cotidiano dos membros nas decisões (3.5) confere ao EES as características adicionais da autogestão, na qual primam mecanismos de democracia direta (Mothé, 1980).

Com base nessa grade tridimensional, podem ser identificados os traços peculiares de um EES particular ou de um segmento específico. Assim, mediante uma análise ex post seria possível agrupá-los em

DADOS - Revista de Ciências Sociais, Rio de Janeiro, vol. 61, nº 1, 2018 
Figura 1

Análise comparativa entre EES

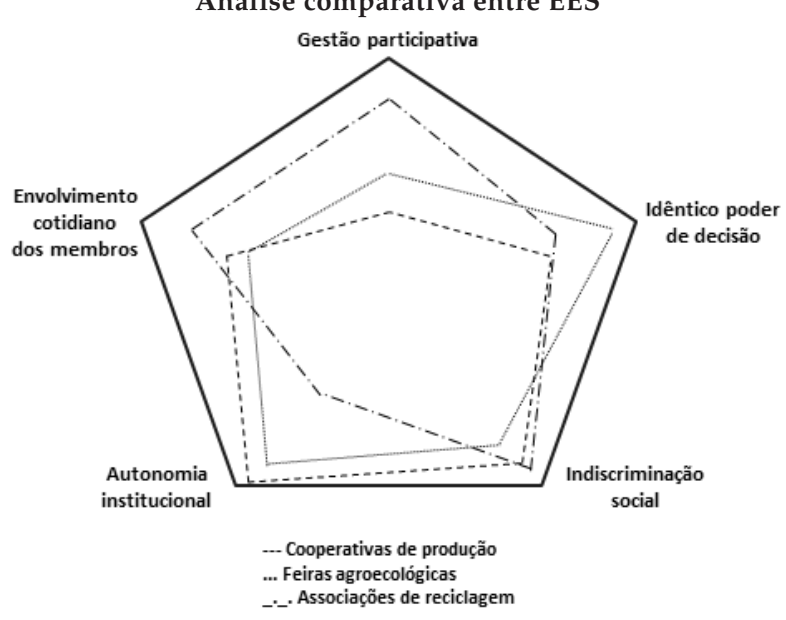

Fonte: Elaboração dos autores.

padrões característicos. Utilizando-se indicadores observacionais apropriados e procedendo por contraste e semelhança entre as propriedades julgadas essenciais à luz do ideal-tipo, pesquisas empíricas serviriam para posicionar tipos de EES uns em relação aos outros, como exemplificado hipoteticamente na Figura 1 no tocante ao atributo geral gestão democrática.

\section{EES E ORGANIZAÇÕES AFINS}

Conforme o ordenamento dos critérios estipulados em cada atributo geral, como já mencionado o modelo típico-ideal é correspondido em níveis mais elevados pelos EES que adotam práticas de autogestão (critério 3.5), se engajam em movimentos de transformação social (2.5) e funcionam com base no trabalho coletivo dos sócios (1.5). Alguns estudos sobre essa "franja superior" da economia solidária demonstram que, em tais casos, as condutas empreendedoras e solidárias conjugam-se mais plenamente, estabelecendo ambientes de mutualidade e favorecendo a compatibilidade entre interesses individuais e coletivos, no âmbito da gestão e da organização do trabalho. No lugar de óbice ou custo adicional, a autogestão passa a exercer um efeito positivo sobre o desempenho econômico, resultando assim em maior satisfação das expectativas pessoais (Gaiger, 2004, 2006). Ao mesmo tempo, o envolvimento na construção de alternativas sociais denota a importância assumida pela razão projetiva, um fator que impulsiona maior ati- 
vismo político dos EES (Gaiger, 2012b). Para ressaltar essas características, propomos designar as organizações correspondentes de Empreendimentos Autogestionários Alternativos (EAA).

No imaginário dos atores empenhados em promover a economia solidária como uma alternativa ou mesmo um sucedâneo à atual economia, os EAA despertam grande interesse e tendem a ser vistos como um modelo exemplar para toda a economia solidária. Mas conquanto eles possam, de fato, personificar estágios mais avançados de socialização dos meios de produção, de exercício do poder pelos trabalhadores e de envolvimento em questões de interesse geral, a análise desse tipo de EES deve ser feita com vagar, tendo em vista o conjunto amplo e heterogêneo de organizações identificadas com a economia solidária.

Assim, se os EAA podem ser considerados, sob algumas condições teóricas, como expressões de uma forma social de produção $0^{13}$ não capitalista ou anticapitalista, é preciso reconhecer que eles constituem um evento singular, cuja ocorrência depende de circunstâncias particulares não generalizáveis. Tomar os EAA como uma referência superior e dela extrair consequências normativas acarreta o risco de idealizar a economia solidária. No terreno da análise, findaria encobrindo e condenando à irrelevância outras manifestações de economia solidária, dotadas de lógicas próprias. Raciocínios metonímicos (Santos, 2002b) como esse nos privariam da tarefa de examinar essa pluralidade de iniciativas, em seus diversos sentidos e possibilidades de desenvolvimento. Ademais, o alargamento do horizonte comparativo, no lugar do seu estreitamento, favorece a identificação de casos híbridos ou defectivos por isso, periféricos em relação ao conceito típico-ideal de EES - mas igualmente de interesse.

A construção de modelos afastados de juízos de valor oferece uma via nessa direção. O primeiro passo, em relação ao problema recémexposto, consistiria em delimitar a abrangência dos conceitos, aclarando suas fronteiras e relações. Podemos visualizá-lo esquematicamente por meio de círculos concêntricos (Figura 2).

a) Ao centro, situam-se os EAA, empreendimentos mais avançados do ponto de vista dos traços típicos da economia solidária, segundo o prisma teórico aqui utilizado. Eles figuram principalmente entre os empreendimentos cuja função precípua é garantir trabalho e renda para seus membros (Gaiger et al., 2014), mas não correspondem às situações empíricas mais frequentes.

DADOS - Revista de Ciências Sociais, Rio de Janeiro, vol. 61, no 1, 2018 
Figura 2

Âmbitos de abrangência dos conceitos

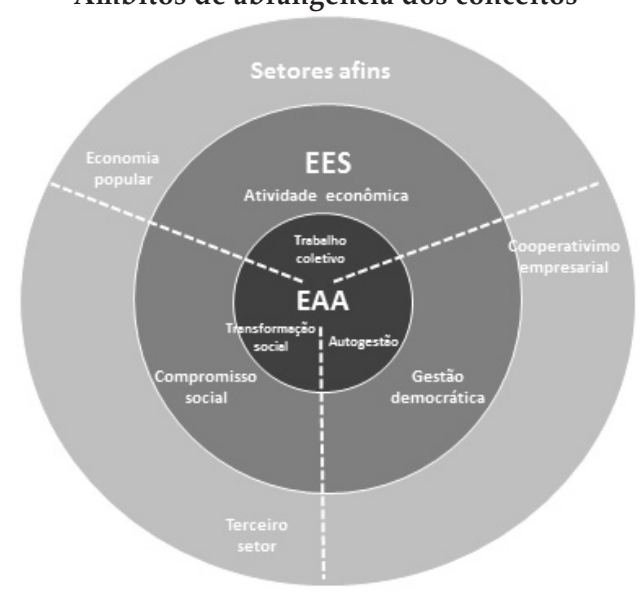

Fonte: Elaboração dos autores.

b) No círculo intermediário, englobando o primeiro, tem-se o conjunto geral de EES de acordo com os critérios propostos. A correspondência dos casos empíricos aos atributos gerais do modelo é variável, mas deve satisfazer pelo menos ao primeiro critério de cada atributo para sua inclusão na economia solidária.

c) As organizações que não se adequam plenamente aos critérios prescritos pelos atributos gerais, mas o fazem num caso ou noutro, podem ser considerados como periféricas ou afins à economia solidária, estando representadas no círculo externo. Em parte, compreendem situações híbridas, nas quais as características da economia solidária mesclam-se com outras, próprias da economia de mercado, da economia pública ou da economia familiar e comunitária. Em parte, trata-se de casos defectivos aos quais faltam determinadas características da economia solidária, como a igualdade de poder entre os sócios ou o exercício de uma atividade econômica permanente.

Em termos mais gerais, pertence a essa terceira órbita um conjunto variado de organizações parcialmente conformes aos atributos gerais dos EES, mas deficientes em um critério fundamental da economia solidária: tais organizações não constituem iniciativas genuinamente criadas ou dirigidas pela associação livre e autônoma dos próprios trabalhadores (consumidores ou usuários), pelo menos não os mesmos que realizam as atividades econômicas. Elas se originam por obra de 
terceiros (microempreendedores, empresários, cidadãos ou entidades), diante dos quais os trabalhadores ou beneficiários encontram-se em dependência funcional, mesmo quando partícipes da organização. Tipicamente, correspondem aos seguintes casos:

c.1) Empreendimentos de economia popular, de caráter familiar ou semifamiliar, nas quais o trabalho é coletivo, mas não aberto à livre adesão, nem exercido em igualdade de condições. Inobservam em geral os critérios de gestão democrática e nem sempre contraem compromissos sociais, ficando limitados à busca dos resultados necessários à sua própria sobrevivência.

c.2) Cooperativas empresariais, cujos sócios via de regra são detentores de negócios privados, nos quais predomina a contratação de trabalhadores. Dão prioridade à sua finalidade econômica e se alinham à lógica do mercado. Observam os critérios cooperativistas de gestão democrática, mas sua dimensão social restringe-se normalmente à defesa do cooperativismo, sem implicar outras ações que não tenham um caráter instrumental para seus interesses econômicos.

c.3) Entidades do terceiro setor, conforme sua definição usual no Brasil (Gaiger, 2009a). Compreendem obras de benemerência ou de atuação social, como associações filantrópicas, fundações e ONGs. Destacam-se pelo cumprimento de uma missão social de interesse público, mas nem sempre desenvolvem alguma atividade econômica ou se governam democraticamente.

Nos termos acima indicados, a proposição de modelos ou variantes do tipo-ideal não deve ficar restrita aos EAA, como vimos, mas tampouco conviria ampliá-la indiscriminadamente às organizações similares e afins em alguns aspectos, mas não propriamente enquadráveis na economia solidária. Note-se a propósito que em alguns países da América Latina convencionou-se a designação "economia social e solidária", mais por comodidade ou interesse em sua unificação vocabular do que por algum entendimento fundamentado conceitualmente. Em resultado disso, os conceitos de economia social e economia solidária são frequentemente utilizados indistintamente, mas de forma imprecisa. No Brasil, igualmente, autores tomam a economia social e a economia solidária como sinônimos (Senhoras, 2005; Magrini et al., 2010). Rigidez e flutuação conceitual não são recomendáveis. Por conta disso, seria oportuno fazer alguns esclarecimentos sobre dois conceitos usuais na

DADOS - Revista de Ciências Sociais, Rio de Janeiro, vol. 61, no 1, 2018 
Luiz Inácio Gaiger, Adriane Ferrarini e Marília Veronese

literatura internacional que se aproximam da economia solidária: a economia social, já referida, e o terceiro setor.

\section{Diferenças e Intersecções entre Campos Sociais}

Ao contrário da Europa, o termo economia social é estranho às instituições, aos atores sociais e ao meio acadêmico no Brasil, salvo exceções ${ }^{14}$. Uma das raras elaborações conceituais a respeito (Serva e Andion, 2006) reconhece que o termo é inusual no país, apesar das organizações que atuam na fronteira entre as esferas econômica e social constituírem um fenômeno expressivo, cada vez mais notável tanto do ponto de vista prático quanto teórico. Em trabalho anterior (Serva e Andion, 2004), destaca-se a necessidade de compreender os impactos que as organizações da economia social sofreram historicamente, o que findou por lhes dar uma fisionomia peculiar, como seu marcado caráter filantrópico e caritativo herdado das obras religiosas. Ditas iniciativas sentiram posteriormente o efeito da profissionalização da assistência social e da criação de sindicatos e entidades similares com atuação social. O surgimento de movimentos sociais e de ONGs no final do regime militar, seguido da renovação da sociedade civil nos anos da redemocratização, contribuiu para politizar os debates e erigir um novo arcabouço institucional, visando ao cumprimento das funções de assistência social como uma tarefa vinculada à esfera pública e às diretrizes emanadas desse espaço de deliberação. Nesse contexto, as dificuldades de identificar um setor específico de economia social resultam em grande parte da dicotomia existente entre economia pública e economia privada. Se ambas possuem âmbitos de intervenção precisos, a economia social acaba sendo deixada em um espaço intermediário, em prejuízo de sua caracterização e delimitação (Caeiro, 2008).

Além do mais, focalizar a economia social no Brasil a partir do tripé clássico reconhecido na Europa esbarraria em uma série de óbices. $\mathrm{O}$ segmento das cooperativas, mais tradicional e bem conhecido, é também eclético quanto aos requisitos de articulação entre as dimensões econômica, social e política, constituindo-se, não raras vezes, em estratégias empresariais de maximização de lucros, apoiadas em relações de trabalho flexíveis e precárias. O segmento das mutualidades não possui identidade própria no Brasil: ele se confunde com as associações, por agregar instituições de tipo associativo e de inscrição facultativa que atuam na área da proteção complementar da segurança social, saúde e qualidade de vida. Suas poucas singularidades, como a contra- 
partida dos sócios ou algum tipo de afiliação profissional, não bastam como traço distintivo. Por fim, o segmento das associações também acolhe uma diversidade de organizações, tanto sociais quanto econômicas. Muitas daquelas que possuem na atividade produtiva sua principal finalidade se inserem na economia solidária, mas correspondem a uma pequena fração desse vasto setor.

Quanto às organizações sociais em geral, quer sejam vistas como parte da economia social ou do terceiro setor, também constituem um campo globalmente heterogêneo, a exigir um exame meticuloso para sua qualificação. Muitas prestam serviços sociais em setores variados, com múltiplos formatos de governança, com ou sem financiamento do estado e de forma mais ou menos profissionalizada. $\mathrm{O}$ fato inovador no Brasil, após a Constituição de 1988, foi a presença dessas organizações na execução e cogestão de políticas públicas. Contudo, a diversidade e a amplitude dessas organizações não favorecem análises tipológicas, salvo mediante uma delimitação prévia dos subsetores de interesse para fins de comparação com outros conceitos de referência.

Por seu turno, o terceiro setor é um conceito com trânsito no Brasil desde os anos 1990 (Fernandes, 1994). Têm sido enquadradas no terceiro setor organizações de variadas origens e formas de atuação. De acordo com a definição canônica, tais organizações possuem em comum o fato de atuarem em questões de interesse público, sendo autônomas do ponto de vista de sua constituição, gestão e dissolução, estando desprovidas de ânimo de lucro. Com tal abrangência, o terceiro setor é inevitavelmente heterogêneo. Combinando critérios morfológicos e institucionais com uma abordagem interpretativa dos seus princípios e lógicas de ação no caso brasileiro, podem-se distinguir três subsetores:

- Um leque amplo de entidades caritativas sem vínculos diretos com o fenômeno recente do terceiro setor. Compreendem organizações tradicionais de caráter filantrópico e assistencial, entidades corporativas ou comunitárias direcionadas à cultura e lazer e, ainda, instituições não estatais, a exemplo das cooperativas de consumo, dos hospitais e das escolas. Essas iniciativas vinculam-se a seus campos específicos de atuação, não mantendo senão uma identidade em sentido lato, o que lhes retira tanto motivos quanto possibilidades de ação conjunta.

- As fundações e os institutos empresariais orientados pelo enfoque da responsabilidade social. Sua atuação normalmente complementa as políticas sociais, incidindo sobre questões incluídas no que essas orga- 
nizações definem como agenda cidadã. Esse subsetor motiva as abordagens mais críticas ao terceiro setor, que o veem como um estratagema de legitimação das classes dominantes, acionado por meio de mecanismos compensatórios que atenuam os custos sociais do modelo econômico, sobretudo no caso dos programas neoliberais. Nessa ótica, o terceiro setor favoreceria a privatização da esfera pública e o enfraquecimento do estado como espaço democrático primordial de transação de interesses e de implantação de políticas universais.

- As organizações não governamentais, ONGs, cuja atuação se orienta normalmente por objetivos de transformação social. Em alguns casos, atuam com outras organizações e companhias privadas em projetos de inclusão social dirigidos a populações de baixos rendimentos, com vistas à sua inserção por via do consumo ou pelo desenvolvimento de capacidades empreendedoras a serem utilizadas no mercado. Em outros casos, mantêm uma abordagem crítica do mercado e da estrutura geral da economia capitalista, apostam no fortalecimento coletivo dos seus beneficiários e valorizam sua autonomia, estimulando formas de participação e decisão democrática. Incluem as entidades de apoio e fomento à economia solidária, as quais, pelas razões já apontadas, via de regra rejeitam sua vinculação ao terceiro setor.

As organizações do terceiro setor são entidades de direito privado que não buscam gerar benefícios pecuniários para seus membros, mas sim responder a demandas de interesse público. Assumem então uma missão social determinada e a cumprem com base em valores de gratuidade, respeito aos direitos humanos, igualdade etc. Articulam-se por meio de conexões horizontais descentralizadas, respeitando a pluralidade e as vocações singulares de cada organização. Desses pontos de vista, há correspondências entre as estruturas e as lógicas de funcionamento do terceiro setor e da economia solidária. Em ambos os casos, as iniciativas primam por sua autonomia institucional, pela criação de redes no lugar de estruturas piramidais e hierárquicas, e por compromissos com a sociedade.

Entretanto, as organizações do terceiro setor em geral descumprem com requisitos pertinentes aos EES. Em primeiro lugar, por não pertencerem a pessoas que se associam e trabalham na organização, realizando elas próprias suas atividades, salvo por vezes os dirigentes. Em segundo, por nem sempre desenvolverem uma atividade econômica. Em terceiro, porque a democracia de gestão é variável, ficando muitas ve- 
zes mitigada ou relegada a procedimentos formais. Em determinados casos, a exemplo das fundações empresariais, é óbvia a sua dependência institucional e econômica em relação às empresas provedoras, responsáveis por sua criação.

Modalidades recentes de atuação empresarial, em conjunto com entidades da sociedade civil, podem ter como desenlace eventual a criação de novas organizações, de natureza social e econômica, comparáveis aos EES. É o caso do incipiente fenômeno do social business, no qual empresas privadas desenvolvem projetos destinados a indivíduos de baixa renda, capacitando-os para o mercado para assim aliviar situações de pobreza, desigualdade e exclusão social (Comini, Barki e Aguiar, 2012). Um resultado prático é a formação de pequenas empresas de propriedade dos beneficiários, sob a forma cooperativa ou com elementos de autogestão, de cujo êxito dependerá a melhoria das condições de vida daquela população e sua sustentabilidade econômica. Contudo, há notórios problemas decorrentes do controle exercido majoritariamente pela empresa responsável pelo projeto, com isso reproduzindo situações de dependência e mesmo de fidelidade à sua marca comercial. Requisitos como autonomia institucional, governança democrática e participação coletiva ficam no geral em plano secundário. Além disso, há uma orientação quase exclusiva para o mercado, embora se reconheça sua insuficiência como via de solução para os problemas da pobreza (Teodósio e Comini, 2012:419), que resultam da própria lógica dos mercados e de dinâmicas estruturais de opressão e exclusão.

Qualificar algumas organizações do terceiro setor como EES não seria impossível. No plano imediato, trata-se de uma questão empírica. Entretanto, há problemas de fundo, a começar pelo fato de que o amplo trânsito alcançado pelo terceiro setor tem a ver com a banalização do conceito, convertido em uma espécie de vade mecum por meio de procedimentos sujeitos a objeções evidentes: a) definir o terceiro setor por exclusão, em relação ao primeiro e segundo setores, o que faz tábula rasa dos contextos históricos e dos espaços reservados a iniciativas não privadas e não estatais, extremamente variáveis; b) enquadrar em seu âmbito iniciativas com as mais diferentes origens e naturezas, desprezando as impropriedades de tais inclusões, que retiram a unidade necessária para que dita realidade seja referida por um único conceito; c) menosprezar o fato de que a crise do Estado e a supervalorização do mercado não estão desvinculadas de estratégicas políticas assumidas 
em parte pelos atores que se perfilam ou são vistos como protagonistas do terceiro setor.

Ademais, a trajetória da economia solidária assemelha-se àquela da economia social na Europa: ao ter em seu centro os EES, tal como na experiência europeia foi integrado o campo recente das empresas sociais, fica nítido o seu contraste com o enfoque original do terceiro setor proposto pelos países anglo-saxônicos. Dito enfoque vincula o terceiro setor ao setor sem fins lucrativos e ao voluntariado, em contraposição ao econômico, no qual o lucro e as relações mercantis e utilitárias seriam de regra. A crítica a essa redução arbitrária, de toda lógica econômica à finalidade de lucro, deixa salientes as diferenças de fato e de percepção entre a experiência norte-americana e a experiência europeia (Evers e Laville, 2004) e favorece uma perspectiva comum Norte-Sul: melhorias nas condições de vida requerem a geração e a partilha de benefícios entre os membros das organizações que as promovem, o que supõe diferenciar a lógica e o lucro capitalistas das demais formas de produção econômica e de geração de excedentes.

Em termos mais gerais, caberia indagar se os fatores que dinamizam as organizações sociais, em suas relações com o mercado e o Estado, podem ser adequadamente compreendidos a partir da noção de setor, no sentido de um campo específico de práticas que se constrói por diferenciação e autonomia diante dos demais. Consideramos mais apropriada e congruente com uma abordagem gradualista a perspectiva da economia plural (Laville, 2006), na qual coexistem diferentes iniciativas, híbridas no sentido de manejarem simultaneamente lógicas econômicas distintas e no sentido de possuírem uma dimensão social e política integrada à sua atuação propriamente econômica. A natureza social ou não lucrativa de algumas dessas iniciativas seria mais bem compreendida no interior dessa totalidade, não como uma propriedade de setores independentes.

(Recebido para publicação em 9 de Março de 2016)

(Reapresentado em 20 de Outubro de 2017)

(Aprovado em 4 de Dezembro de 2017) 
O Conceito de Empreendimento Econômico Solidário

\section{NOTAS}

1. Trata-se do International Comparative Social Enterprise Models Research Project (ICSEM Project), que conta com mais de 200 investigadores, de 50 países. Informações disponíveis em: http://emes.net/research-projects/social-enterprise/icsem-project/.

2. A adoção do termo economia solidária, bem como as visões a ele subjacentes, foi objeto de uma tese de sociologia do conhecimento (Lechat, 2004).

3. O Conselho Nacional de Economia Solidária, instalado em 2006, constitui o órgão maior da esfera pública, agrupando representações dos empreendimentos, de diversos setores do Estado e da sociedade civil. Já o Fórum Brasileiro de Economia Solidária, criado em 2003, tem sido o principal responsável pelos encontros e mobilizações nacionais.

4. Disponível em: http://www.fbes.org.br/index.php?option=com_docman\&task =cat_view\&gid=332\&Itemid=18.

5. Ver http://portal.mte.gov.br/data/files/FF8080814373793B0143BB0889 3640E8/Texto de Referência - gráfica.pdf.

6. Um trabalho ímpar de convergência entre estudiosos de diferentes nacionalidades, com predominância inicial da América Latina, deu origem ao Dicionário Internacional da Outra Economia (Cattani et al., 2009), já reeditado em vários países.

7. Nesse trabalho são examinadas em pormenor as bases epistemológicas e metodológicas que sustentam a pesquisa militante, avaliando-se em contrapartida seus pontos vulneráveis e suas principais limitações.

8. Weber (1989:107-114) sublinha três características fundamentais dos tipos-ideais: sua racionalidade (contêm relações lógicas, providas de significado para o cientista, rigorosamente separadas da noção de "dever-ser" ou de "exemplar"), sua unilateralidade (contêm apenas facetas selecionadas por sua relevância, enfatizadas ou acentuadas mentalmente) e seu caráter utópico ou abstrato (existem no plano das ideias, não dos fenômenos, nos quais jamais se corporificam plenamente).

9. O termo racionalidade significa não apenas que as características apontadas são frequentes, aceitas e compartilhadas pelos EES, mas que se articulam organicamente, se reforçam e se combinam, estabelecendo uma dinâmica objetiva para a ação dos indivíduos, uma pressão estrutural para que procedam de certa maneira, precisamente porque, no contexto assim criado, tal comportamento se assevera mais apropriado (Gaiger, 2006).

10. Os indicadores propriamente ditos variam conforme a metodologia e as condições técnicas de cada pesquisa. Por isso, no modelo de referência é preferível estipular critérios de caráter mais geral.

11. Para uma visão panorâmica, ver Gaiger e Corrêa (2010).

12. Membros abarcam também participantes não sócios, como voluntários e trabalhadores assalariados

13. O conceito provém de um estudo da teoria de Karl Marx sobre a transição entre modos de produção (Gaiger, 2007b). Significa que nos EAA modificam-se os princípios e fins da organização econômica, bem como se alteram as relações que os indivíduos contraem entre si, no que tange aos meios de produção, ao processo de trabalho e a

DADOS - Revista de Ciências Sociais, Rio de Janeiro, vol. 61, nº 1, 2018 


\section{Luiz Inácio Gaiger, Adriane Ferrarini e Marília Veronese}

seus resultados. Em consequência, uma nova lógica (ou forma) passa a presidir o agenciamento dos fatores produtivos.

14. Um dos poucos livros publicados sobre a economia social no Brasil (Dowbor e Kilsztajn, 2001) traz um conjunto de experiências, principalmente de prestação de serviços sociais por entidades privadas sem ânimo de lucro, mas não apresenta elementos de ordem conceitual ou tipológica. 


\section{REFERÊNCIAS BIBLIOGRÁFICAS}

BOUCHARD, Marie; CRUZ FILHO, Paulo; SAINT-DENIS, Martin. (2011), “Cadre Conceptuel pour Définir la Population Statistique de l'Économie Sociale au Québec". Cahiers de la Chaire de Recherche du Canada en Économie Sociale, R-2011-01. Montréal, Chaire de Recherche du Canada en Économie Sociale/CRISES.

CAEIRO, Joaquim. (2008), "Economia Social: Conceitos, Fundamentos e Tipologia". Katálysis, vol. 11, no 1, pp. 61-72.

CATTANI, Antonio et al. (eds.). (2009), Dicionário Internacional da Outra Economia. Coimbra, Almedina.

COMINI, Graziella; BARKI, Edgard; AGUIAR, Luciana de. (2012), "A Three-pronged Approach on Social Business: A Brazilian Multi-case Analysis". Revista de Administração, vol. 47, no 3, pp. 385-397.

DA SILVA, Regilane F.; SILVA, Sandro P. (2015), "Em Busca de um Marco Legal para a Economia Solidária no Brasil: Análise da Trajetória do PL 4.685/2012". Mercado de Trabalho, no 58, Ipea.

DEFOURNY, Jacques; NYSSENS, Marthe. (2012), “The EMES Approach of Social Enterprise in a Comparative Perspective". EMES European Research Network Working Paper Series, no 3/2012.

(eds.). (2013), “The 'International Comparative Social Enterprise Models' (ICSEM) Project". Liège/Bruxelles, Centre d'Économie Sociale.

DOWBOR, Ladislau; KILSZTAJN, Samuel (orgs.). (2001), Economia Social no Brasil. São Paulo, Senac.

EVERS, Adalbert; LAVILLE, Jean-Louis (eds.). (2004), The Third Sector in Europe. Cheltenham, Edward Elgar.

FERNANDES, Rubem. (1994), Privado, porém Público: O Terceiro Setor na América Latina. Rio de Janeiro, Relume-Dumará.

FERRARINI, Adriane; VERONESE, Marília. (2010), “Piracema: Uma Metáfora para o Microempreendedorismo Associativo no Brasil". Otra Economía - Revista Latinoamericana de Economía Social y Solidaria, vol. IV, no 7, pp. 131-152.

GAIGER, Luiz. (1996), “Empreendimentos Solidários: Uma Alternativa para a Economia Popular?", in L. Gaiger (ed.), Formas de Combate e de Resistência à Pobreza. São Leopoldo, Unisinos, pp. 101-126.

(ed.). (2004), Sentidos e Experiências da Economia Solidária no Brasil. Porto Alegre, UFRGS.

. (2006), "A Racionalidade dos Formatos Produtivos Autogestionários". Sociedadee Estado, vol. 21, no 2, pp. 513-544.

. (2007a), “A Outra Racionalidade da Economia Solidária. Conclusões do Primeiro Mapeamento Nacional no Brasil”. Revista Crítica de Ciências Sociais, no 79, pp. 57-77.

. (2007b), “La Economía Solidaria y el Capitalismo en la Perspectiva de las Transiciones Históricas", in J. Coraggio (ed.), La Economía Social desde la Periferia; Contribuciones Latinoamericanas. Buenos Aires, Altamira, pp. 79-109.

DADOS - Revista de Ciências Sociais, Rio de Janeiro, vol. 61, n 1, 2018 


\section{Luiz Inácio Gaiger, Adriane Ferrarini e Marília Veronese}

(2009a), “Empreendimento Econômico Solidário, in A. Cattani et al. (eds.), Dicionário Internacional da Outra Economia. Coimbra, Almedina, pp. 181-187.

. (2009b), "Antecedentes e Expressões Atuais da Economia Solidária”. Revista Crítica de Ciências Sociais, no 84, pp. 81-99.

. (2012a), “Por um Olhar Inverso: Prismas e Questões de Pesquisa sobre a Economia Solidária". Sociedade e Estado, vol. 27, no 2, pp. 313-335.

(2012b), “La Présence Politique de l’Économie Solidaire. Considérations à partir de la Première Cartographie Nationale", in I. Georges ; M. Leite (eds.), Les Nouvelles Configurations du Travail et l'Économie Sociale et Solidaire au Brésil. Paris, L'Harmattan, pp. 231-258.

(2015), "Collaborative Research between Civil Society, State and the Academia. Lessons from the Brazilian Mapping of the Solidarity Economy", in M. Bouchard e D. Rousselière (eds.), The Weight of the Social Economy. An International Perspective. Pieterlen, Peter Lang AG, pp. 205-230.

. (2017), "O Espírito da Reciprocidade", in L. Gaiger; A. dos Santos (orgs.), Solidariedade e Ação Coletiva; Trajetórias e Experiências. São Leopoldo, Ed. Unisinos, pp. 275-304.

GAIGER, Luiz; CORRÊA, Andressa. (2010), “A História e os Sentidos do Empreendedorismo Associativo". Otra Economía - Revista Latinoamericana de Economía Social y Solidaria, vol. IV, no 7, pp. 153-176.

; LAVILLE, Jean-Louis. (2009), “Economia Solidária”, in A. Cattani et al. (eds.), Dicionário Internacional da Outra Economia. Coimbra, Almedina, pp. 162-168.

GAIGER, Luiz et al. (2014), A Economia Solidária no Brasil. Uma Análise de Dados Nacionais. São Leopoldo, Oikos.

GARDIN, Laurent; LAVILLE, Jean-Louis. (2017), “L'Économie Solidaire”, in J. Defourny; M. Nyssens (eds.), Économie Sociale et Solidaire; Socioéconomie du ze Secteur. Louvain-la-Neuve, De Boeck Supérieur, pp. 188-219.

LAVILLE, Jean-Louis. (2006), “Économie Plurielle”, in J.-L. Laville; A. Cattani (eds.), Dictionnaire de l'Autre Économie. Paris, Gallimard, pp. 250-258.

LAWRENCE, Thomas; SUDDABY, Roy. (2006), "Institutions and Institutional Work", in S. Clegg et al. (eds.), Handbook of Organization Studies. 2a ed. London, Sage, pp. 215-254.

LECHAT, Noëlle. (2004), Trajetórias Intelectuais e o Campo da Economia Solidária no Brasil. Tese (Doutorado em Ciências Sociais), Unicamp, Campinas.

LEITE, Márcia. (2009), “A Economia Solidária e o Trabalho Associativo: Teorias e Realidades". Revista Brasileira de Ciências Sociais, vol. 24, no 69, pp. 31-51.

LIMA, Jacob. (2012), “Cooperativas, Trabalho Associado, Autogestão e Economia Solidária: A Constituição do Campo de Pesquisa no Brasil, in I. Georges; M. Leite (eds.), Novas Configurações do Trabalho e Economia Solidária. São Paulo, Annablume, pp. 195-221.

MAGRINI, Rosas; et al. (2010), “Economia Social no Contexto Brasileiro: Considerações sobre o Caráter Desigual do Trabalho das Mulheres". Observatorio de la Economía 
Latinoamericana [on line], no 137 Disponível em http://www.eumed.net/cursecon/ecolat/br/. Acesso em 04/03/2016.

MOTHÉ, Daniel. (1980), L'Autogestion Goutte à Goutte. Paris, Centurion.

NYSSENS, Marthe. (1996), “Économie Populaire au Sud, Économie Sociale au Nord: Des Germes d'Économie Solidaire?", in P. Sauvage et al. (eds.), Réconcilier l'Économique et le Social. Paris, OCDE, pp. 95-120.

(ed.). (2006), Social Enterprise. Adingdon/New York, Routledge.

RAZETO, Luis. (1983), Las Organizaciones Económicas Populares. Santiago, Programa de Economía del Trabajo.

. (1990), Las Empresas Alternativas. Montevidéu, Editorial Nordan-Comunidad.

(1993), "Economia de Solidariedade e Organização Popular", in M. Gadotti; F. Gutiérrez (eds.), Educação Comunitária e Economia Popular. São Paulo, Cortez, pp. 34-58.

SANTOS, Boaventura de Sousa Santos (ed.). (2002a), Produzir para Viver; os Caminhos da Produção não Capitalista. Rio de Janeiro, Civilização Brasileira.

(2002b), "Para uma Sociologia das Ausências e uma Sociologia das Emergências". Revista Crítica de Ciências Sociais, no 63, pp. 237-280.

SENHORAS, Elói. (2005), “A Economia Social em Perspectiva Transversal no Brasil e no Canadá". Administração Pública e Economia, no 5, pp. 139-151.

SERVA, Maurício; ANDION, Carolina. (2004), "Por uma Visão Positiva da Sociedade Civil: Uma Análise Histórica da Sociedade Civil Organizada no Brasil". Cayapa - Revista Venezolana de Economía Social, vol. 4, no 7, pp. 7-24.

. (2006), “Uma Delimitação do Campo da Economia Social no Brasil: História, Correntes e Atores". Anais do 30 Encontro da ANPAD, Salvador.

SILVA, Marcelo; OLIVEIRA, Gérson. (2011), “A Face Oculta(da) dos Movimentos Sociais: Trânsito Institucional e Intersecção Estado-Movimento: Uma Análise do Movimento de Economia Solidária no Rio Grande do Sul". Sociologias, vol. 13, no 28, pp. 83-124.

TEODÓSIO, Armindo; COMINI, Graziella. (2012), “Inclusive Business and Poverty: Prospects in the Brazilian Context". Revista de Administração, vol. 47, no 3, pp. 410-421.

WEBER, Max. (1989), “A 'Objetividade' do Conhecimento nas Ciências Sociais", in G. Cohn (ed.), Weber; Sociologia. (4a ed.). São Paulo, Ática, pp. 79-127.

DADOS - Revista de Ciências Sociais, Rio de Janeiro, vol. 61, nº 1, 2018 
Luiz Inácio Gaiger, Adriane Ferrarini e Marília Veronese

RESUMO

O Conceito de Empreendimento Econômico Solidário: Por uma Abordagem Gradualista

O artigo apresenta inicialmente como uma confluência havida nos anos 1990 entre diversos atores sociais no Brasil conduziu a uma unidade política em torno do conceito de empreendimento econômico solidário. Discute a seguir as conveniências e inadequações desse enfoque, essencialmente normativo, para fins acadêmicos, atividade que implica identificar os traços estruturantes de tais organizações e formular critérios de qualificação e diferenciação desse campo de práticas. Propõe, desta maneira, uma modelagem weberiana idealtípica do conceito, apropriada a análises empíricas desde um prisma teórico predeterminado. Lastreado em estudos precedentes dos autores, o exame do grau de correspondência entre as organizações econômicas concretas e os critérios prescritos pelo modelo permite qualificá-las, relacioná-las a organizações congêneres e comparar a economia solidária com campos de práticas afins, dentre eles o terceiro setor, examinado em suas peculiaridades na última seção do artigo.

Palavras-chave: conceito tipo-ideal; economia solidária; economia social; cooperativismo; terceiro setor

\section{ABSTRACT}

The Concept of Solidarity Economy Venture: Towards a Gradualist Approach

The following article begins by demonstrating how a convergence between various social actors in 1990s Brazil led to a political consensus on the concept of an empreendimento econômico solidário [solidarity economy venture]. It then discusses the advantages and disadvantages of what is essentially a normative focus, for academic purposes, leading us to identify the structural elements of such organizations and to formulate qualification and differentiation criteria in this field of practice. It thus proposes a Weberian ideal-type model for the concept, appropriated for empirical analyses from a pre-determined theoretical prism. Backed by several of the authors' previous studies, an examination of the degree of correspondence between the specific economic organizations and the criteria prescribed by the model allows us to qualify and relate them to peer organizations and to compare the solidarity economy with similar fields of practice, such as the third sector, examining particular features in the final section of the article.

Key words: ideal-type concept; charity economy; social economy; cooperativism; third sector 
RÉSUMÉ

Le Concept de l'Entreprenariat Économique Solidaire: Pour une Approche Gradualiste

Cet article présente initialement de quelle manière une confluence survenue dans les années 1990 entre divers acteurs sociaux du Brésil a pu conduire à une unité politique autour du concept d'entreprenariat économique solidaire. On discutera ensuite des avantages et des inconvénients de cette approche, essentiellement normative, à des fins académiques, ce qui impliquera l'identification des traits structurants de telles organisations et la formulation des critères de qualification et de différenciation de ce champ de pratiques. On proposera ainsi une modélisation wébérienne idéale-typique du concept, qui s'avère appropriée pour les analyses empiriques sous un prisme théorique prédéterminé. Sur la base de des précédentes études des auteurs, l'examen du degré de correspondance entre les organisations économiques concrètes et les critères prescrits par le modèle permettra de les qualifier, de les mettre en relation avec des organisations similaires et de comparer l'économie solidaire avec des champs de pratique du même ordre, à l'instar du tiers-secteur, dont on examinera les particularités dans la dernière partie de cet article.

Mots-clés: concept idéal-typique; économie solidaire; économie sociale; coopérativisme; tiers-secteur

\section{RESUMEN}

El Concepto de Iniciativas de Economía Solidaria: Hacia una Perspectiva Gradualista

El artículo presenta inicialmente la manera en que la confluencia que se produjo en la década de 1990 entre diversos actores sociales en Brasil condujo a una unidad política en torno al concepto de iniciativas económicas solidarias (conocidas en Brasil como empreendimentos econômicos solidários). A continuación, se debaten las ventajas e inconvenientes de este enfoque, esencialmente normativo, para fines académicos, una actividad que implica identificar los rasgos estructurales de tales organizaciones y formular criterios de calificación y diferenciación de este campo de prácticas. Se propone, de esta manera, una configuración weberiana ideal típica del concepto, apropiada para análisis empíricos realizados desde un prisma teórico predeterminado. Fundamentado en estudios precedentes de los autores, el examen del grado de correspondencia entre las organizaciones económicas concretas y los criterios prescritos por el modelo permite calificarlas, relacionarlas con organizaciones congéneres y comparar la economía solidaria con campos de prácticas afines, entre ellos, el tercer sector, cuyas peculiaridades se examinan en la última sección del artículo.

Palabras clave: concepto del tipo ideal; economía solidaria; economía social; cooperativismo; tercer sector 